\section{Biological Protection in Deep Space Missions}

\author{
Lembit Sihver ${ }^{1,2.3 \odot}$, Seyed Mohammad Javad Mortazavi4*๑
}

\begin{abstract}
During deep space missions, astronauts are exposed to highly ionizing radiation, incl. neutrons, protons and heavy ions from galactic cosmic rays (GCR), solar wind (SW) and solar energetic particles (SEP). This increase the risks for cancerogenisis, damages in central nervous system (CNS), cardiovascular diseases, etc. Large SEP events can even cause acute radiation syndrome (ARS). Long term manned deep space missions will therefor require unique radiation protection strategies. Since it has been shown that physical shielding alone is not sufficient, this paper propose pre-flight screening of the aspirants for evaluation of their level of adaptive responses. Methods for boosting their immune system, should also be further investigated, and the possibility of using radiation effect modulators are discussed. In this paper, especially, the use of vitamin $\mathrm{C}$ as a promising non-toxic, cost-effective, easily available radiation mitigator (which can be used hours after irradiation), is described. Although it has previously been shown that vitamin $\mathrm{C}$ can decrease radiation-induced chromosomal damage in rodents, it must be further investigated before any conclusions about its radiation mitigating properties in humans can be concluded.
\end{abstract}

Citation: Sihver L, Mortazavi SMJ. Biological Protection in Deep Space Missions. J Biomed Phys Eng. 2021;11(6):663-674. doi: $10.31661 /$ jbpe.v0i0.1193.

\section{Keywords}

Space Radiation; Radiation Risk; Deep Space; Astronauts; Mars Mission; Biological Protection; Radiation Protection

\section{Introduction}

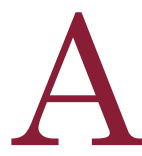

stronauts on long duration deep space missions require reliable radiation protection to protect them from the exposure to high charge and energy (HZE) particles, neutrons and other densely ionizing radiation [1]. The opportunity to launch a spacecraft on a minimum-energy transfer orbit from Earth to Mars occurs about every 25-26 months, when there is an elliptical orbit where the periapsis is at Earth's distance from the Sun and the apoapsis is at Mars' distance from the Sun. This so called Hohmann transfer orbit determines a fixed time of around 9 months to travel from Earth to Mars. However, it is possible to travel to Mars faster but then a higher energy consumption is required. A rather new suggested type of transfer from Earth to Mars is to end in a ballistic capture, which was first used by the Japanese spacecraft Hiten in 1991 as a method to get to the Moon. This results in a substantial savings in capture $\Delta v$ from that of a classical Hohmann transfer orbit under certain conditions. This is accomplished by first becoming captured at Mars, very distant from the planet, and then from there following a ballistic capture transfer to a desired altitude within a ballistic capture
${ }^{1} \mathrm{PhD}$, Department

of Radiation Physics,

Atominstitut, Technische

Universität Wien, Stadi-

onallee 2, 1020 Vienna.

Austria

${ }^{2} \mathrm{PhD}$, Department

of Physics, Chalmers

University of Technology,

41296 Gothenburg,

Sweden

${ }^{3} \mathrm{PhD}$, Centre for Biomed

ical Physics, School of

Healthcare and Medical

Sciences, Sunway Uni-

versity, Jalan Universiti,

Bandar Sunway, 47500

Selangor Darul Ehsan,

Malaysia

${ }^{4} \mathrm{PhD}$, Department of

Medical Physics, Shiraz

University of Medical Sci-

ences, Shiraz, Iran

*Corresponding author:

Seyed Mohammad

Javad Mortazavi

Department of Medical

Physics, Shiraz Univer-

sity of Medical Sciences,

Shiraz, Iran

E-mail: mortazavismj@ gmail.com

Received: 31 May 2019 Accepted: 20 July 2019 
set. Using ballistic capture is predicted to be safer than using a classical Hohmann transfer orbit, as there is no time critical insertion burn, launchable at almost any time (rather than having to wait for a narrow window of opportunity), and more fuel efficient than a normal short time transfer. A human mission to Mars will therefore vary from 6 to 9 months each way, depending on the mission design [2], and the crew will be exposed to densely ionizing radiation for a significant period of time. This may cause different health risks which are discussed in previously published papers $[2,3]$. The exposure to cosmic rays can considerably increase the risk of e.g. cancer, cardiovascular diseases, and damages of the central nervous system (CNS). If exposed to sudden high levels of ionizing radiation, from e.g. a large solar particle event (SPE), the astronauts can even get acute radiation syndrome (ARS). The measurements performed on the Mars Science Laboratory (MSL) robotic space probe mission to Mars during 2012-13 [4] showed that the dose equivalent rate from GCR in deep space was $1.84 \pm 0.30 \mathrm{mSv} /$ day, which means that even with an optimized mission planning and realistic passive shielding, the astronauts would get $0.7 \pm 0.1 \mathrm{~Sv}$ [4]. The dose equivalent rate from GCR is lower on the surface of Mars mainly due to the shielding from the planet, but still $0.70 \pm 0.17 \mathrm{mSv} /$ day. Measures to protect the astronauts must therefore be developed before humans will be able to safely travel to Mars and stay there. Since, it has been shown, see e.g. [5-7], that passive shielding might not be enough to reduce the radiation risks for long term deep space missions, there is a need for other counter measures, e.g. medical counter measures such as radio-protectors and radio-mitigators. A number of radiation effect modulators, which might be used on future deep space missions, have already been developed and tested by different groups, see e.g. [7] and references cited therein. However, in this paper we will concentrate on adaptive response and the use of vitamin $\mathrm{C}$ as a promis- ing non-toxic, cost-effective, easily available radiation mitigator.

\section{Discussion}

\section{Adaptive Response in Space Re-} search

The health effects of sparsely ionizing low dose radiation have been studied for decades [8-12].

Adaptive response is a form of cellular response that can be induced by low doses of radiation followed by a higher challenging dose of radiation. For example, it has been shown that adaptive responses, including DNA repair and antioxidation reactions can be induced following exposures to low doses of sparsely ionizing radiations such as $\mathrm{X}$ - and $\gamma$-rays. As stated by Feinendegen et al. the decrease of damage from endogenous sources by adaptive protection at low doses can be equal to, or larger than, the induction of radiogenic damage [13]. Therefore, the empirical linear nothreshold (LNT) model for estimation of the stochastic health effects of low doses of ionizing radiation might not be valid and reevaluation might be needed [14]. In the beginning of the 2000, a revised model for estimation of the reduction of the radiation risks due to adaptive response in a long duration deep space mission was presented $[15,16]$. This has been followed by several publications presenting adaptive and bystander effects that might protect human cells against DNA damage caused by a subsequent exposure to energetic ion exposure, see e.g. [17-19]. A recent publication confirms the key role of biological protection of astronauts [20], an issue discussed in detail in some new publications [21-23]. The consistency of our previous work [24, 25] and others $[26,27]$ was noted by Cortese et al. who published this report. There is a strong evidence of a wide range of adaptive responses among different individuals, suggesting that medical selection of the astronaut candidates based on in vitro screening of the adaptive responses 
might decrease the radiation induced health risks in deep space [25-27]. A key factor is the effect of the space radiation on the organism's integrated protection systems (e.g., DNA repair and immune system response) against biomolecular damage induced by ionizing radiation. A model has been suggested for the screening and selection of astronauts based on their level of radioadaptation in ground-based in vitro tests [28].

In some recently published papers [28, 29], it is stated that instead of selecting the most radioresistant individuals, we should choose those who show the highest levels of adaptive response. The essential point of radioadaption is to improve the radiation stability through a variety of processes including synthesis of DNA repair enzymes, increasing the concentration of oxidants and other substances that together form radioresistance.

Thus, we noted a number of considerations related to the data provided by Cortese et al, [20]. The following considerations summarize the key points of our proposed biological model:

1. There are individual differences in radioadaptation. These differences vary from a limited effect to significant radioadaptation. Some individuals may even exhibit a form of synergism and the development of more adverse biological effects.

2. Candidates for deep space missions could be screened for a variety of physiological and psychological conditions including radioadaptation.

3. The ability for radioadaptation of each candidate could be quantified by in vitro testing (e.g., exposing blood samples to a low adapting dose of ionizing radiation followed by a high challenging dose) with the associated measurement of biological damage (e.g., chromosome aberrations, DNA damage, and oxidative stress).

4. The level of radioadaptation of each candidate could be evaluated and, if possible, quantified.
5. Candidates with a high level of radioadaptation should be considered for crew assignments for a deep space mission.

6 . When being in space, the selected astronauts will receive conditioning doses of ionizing radiation during exposure to the ambient, chronic GCR.

7. Following the lower conditioning doses rates of ionizing radiation, that promotes the induction of an adaptive response, the astronauts might better tolerate sudden high doses from solar particle events (SPEs). Exposure to strong SPEs can lead to very large doses of energetic particles even behind the spacecraft shielding.

8. Selection of candidates with a high level of radioadaptation, due to e.g. an increased ability to adaptive response, could reduce their risks for severe radiation illness. However, the phenomena must be studied in much more details before any conclusion can be made.

Other considerations are less well quantified and will be more difficult to determine. First, Earth based studies do not fully simulate the effects of microgravity. With no preferred direction in space, bodily processes depending upon earth gravity will function differently in space. The prolonged effects of microgravity and the GCR and SPE, as well as their possible combinatory effect on the human organism are uncertain. However, astronauts with high levels of radioadaptation will have better chances of functioning in a deep space environment.

Second, the elevated radiation fields from GCR and their inclusion of HZE particles are difficult to simulate on earth. Exposing blood samples short time periods to high dose rates of a single heavy ion type (e.g., ${ }^{56} \mathrm{Fe}$ nuclei) does not accurately simulate the risks astronauts are exposed to when they are exposed to lower dose rates of mixed ions over longer time periods, as in the GCR radiation environment.

Third, established biological effects (e.g., the oxygen, bystander, and dose fractionation effects) may be altered as the deep space mis- 
sion duration proceeds. It should be noted that more extravehicular activities (EVAs) are expected in future space missions and EVAs may expose astronauts to high-energy space radiation while breathing $100 \%$ oxygen [30]. Therefore, exposure to space radiation while breathing $100 \%$ oxygen may cause oxidative stress and neuroinflammation [30]. Regarding non-targeted effects, some evidence shows that there are in vivo space radiation-induced non-targeted effects $[31,32]$ which can be observed as late as 20 months after the exposure [33]. Although reasonable judgments regarding these effects during space missions can be inferred, actual operational data must verify this expectation.

Furthermore, a 2016 NASA report [34] stress the importance of better understanding adaptive response and its possible application in deep space missions. The NASA report also confirms that it would be realistic to expect that cells will be exposed to multiple hits of protons before being traversed by an HZE particle (e.g. ${ }^{56} \mathrm{Fe}$ ions).

It is well known that a pre-exposure to low dose radiation of sparsely ionizing radiation, e.g. photons, can stimulate the defense mechanisms such as increasing antioxidant levels reducing the endogenous DNA damage, increasing DNA repair capacity, and increasing apoptosis of damaged cells [13]. It should be noted that Ramadan et al. have previously shown that a low dose of protons can prevent the biological responses to a subsequent challenge dose of heavy ions $(0.1 \mathrm{~Gy}$ of protons 24 hours prior to $0.5 \mathrm{~Gy}$ of ${ }^{56} \mathrm{Fe}$ ) [35]. Moreover, Buonanno have shown that exposure of normal human fibroblasts to $20 \mathrm{cGy}$ of 0.05 or $1-\mathrm{GeV}$ protons protects the irradiated cells against chromosomal damage induced by a subsequent exposure to $50 \mathrm{cGy}$ from $1 \mathrm{GeV} / \mathrm{u}$ iron ions [36]. Zhou et al. [37] have reported that calculations performed by Curtis and Letaw [38] indicate that the nucleus of a cell in a space traveler shielded by $0.4 \mathrm{~g} / \mathrm{cm}^{2}$ of aluminum (which is however an unrealistic thin shield) would be hit by 400 protons and about 0.4 HZE particles during a 3-year Mars mission [38, 39]. Thus most astronauts' cells would be hit by a proton(s) before being hit by an HZE particle.

Cells which are first exposed to multiple hits of protons from the GCR, prior to being traversed by an HZE particle, might be influenced by adaptive response and to some extent protected against future exposures. It has therefore been suggested that before any deepspace manned mission, the adaptive response of all candidates should be measured by ground-based routine cytogenetic tests $[7,14$, $20,21]$. If the theory presented in refs $[7,14]$ is correct, the constant exposure to elevated levels of space radiation from the GCR would serve as adapting "dose" and hence decrease their radiation susceptibility to potential high levels of exposure, i.e. from large SPEs.

\section{Radioadaptation of Microorganisms in space}

The challenging issue of bacterial growth under microgravity conditions in space experiments and its associated physiological responses, which range from modified cell morphology and growth dynamics to a putative increased tolerance to antibiotics, have been addressed recently [40]. Aunins et al. [40] note that E. coli grown aboard the ISS showed resistance against increasing concentrations of the antibiotic gentamicin compared to identical ground controls (experiments conducted on Earth). They especially note that E. coli adapted to grow at higher antibiotic concentrations in space showed consistent changes in expression of 63 genes in response to an increase in drug concentration. The authors concluded that the increased resistance against antibiotics in microgravity can be due to both diminished transport processes and a resultant antibiotic cross-resistance response conferred by an overlapping effect of stress response genes. Although the paper authored by Aunins et al. [40] addresses a challenging 
issue, they are omitting the possibility that the space radiation might have induced adaptation phenomena in the bacteria and that this might have caused the observed bacterial resistance against antibiotics. Substantial evidence shows induction of radiation-induced adaptive response in bacteria. It has been shown that bacteria can become more resistant to antibiotics after receiving a mild physical stressor (e.g. pre-exposure to ionizing electromagnetic [41] or non-ionizing electromagnetic radiation [42]. Given these observations, any low-level initial stress (e.g. exposure to chronic galactic space radiation or acute solar particle events) can alter the bacterial resistance to antibiotics. Some evidence shows that this type of adaptive response may be life-threatening in space. However, this issue cannot be well understood before additional data becomes available. During long-term space missions, the combined effect of space radiation (GCR and SPE) and microgravity might also affect the susceptibility of bacteria to antibiotics. Moreover, factors such as immunosuppression, increased bacterial virulence, and presence of particles in suspension are involved in increased risk of infection in space [43]. It has been reported that even in the absence of immune dysregulation, factors such as increased microbial virulence during spaceflight [44], can increase the risk of infectious disease in space crew [45].

\section{Radioprotectors vs Radiation Miti- gators}

Oxidative damage induced by prolonged exposure to ionizing radiation during space flights has been reported by some researchers [46]. Astronauts' visual systems, particularly the central and peripheral photoreceptors of the retina, are among the organs most affected by cosmic radiation [47]. In space research, studies on mitigators have mostly been focused on developing drugs to reduce carcinogenesis of whole body exposures [48]. In vivo protection against detrimental effects of radiation by chemicals dates back to more than 60 years ago. After September $11^{\text {th }}$ terrorist attacks, 2001, new funding became available for development of medical countermeasures for major threats such as radiological, nuclear, biological, and chemical hazards. Therefore, in U.S. and many other countries studies on biological effects of radiation that furthered the development of prophylactic and therapeutic agents were supported [49].

In 2008, a diet supplemented with the antioxidants plus coenzyme Q10 was evaluated for its ability to prevent carcinogenesis in rodents exposed to different forms of space radiation (protons and HZE particles). This study showed that dietary supplements could be effective in the prevention of malignancies and other neoplastic lesions induced by exposure to space radiation [50].

As long-term exposure to GCR and SPE may increase the risks for cataract, cancers, and cardiovascular diseases [51-55], antioxidants with considerable effectiveness and low toxicity, have been also introduced to protect against relatively low levels of radiation [56]. Even dietary supplementation with dried plum has been reported to prevent the radiation induced skeletal effects such as bone loss either in space or on Earth [57]. Moreover, treatment with soybean-derived Bowman-Birk inhibitor (BBI), BBI concentrate (BBIC) or antioxidants has been shown to prevent, at least to some extent, the adverse biological effects of space radiation [58]. D-selenomethionine is also introduced as a potential countermeasure against the detrimental effects of space radiation [59]. Melanins, biomolecules which are capable of shielding ionizing radiation, can also be used for interplanetary manned space missions [60].

In contrast to treatments of low-levels of ionizing radiation exposures, pharmacological countermeasures should be used for treatments of life-threatening, high level radiation exposures, as e.g. occur when exposed to large SPEs. Although large SPEs are rare, during a large event the fluence of protons with ener- 
gies greater than $30 \mathrm{MeV}$ can be more than $10^{10} \mathrm{~cm}^{-2}$ in several hours or days [61]. Therefore, if crew and equipment are not adequately protected, these events can lead to deposition of large ionizing radiation doses. Despite advances in technology, it is still difficult to predict the occurrence of these large events and giving enough time of warning before the onset of large SPEs seems to be unrealistic [61]. Due to unpredictable SPEs, astronauts face the risk of blood cell death which causes disruption of the immune system as well as increased susceptibility to different infections [62]. Although that SPEs which produce doses $>1$ Gy are rare, the likelihood for doses that can induce prodromal risks is considerable [63]. There are reports which estimate that the astronauts' effective doses can be as high as several Sv during solar flare events. "Ancedotal reports" suggest that Amifostine may have been carried by US astronauts on their trips to the moon (Hall, 2012 [64]), to be used in case of a solar flare event when astronauts could be exposed to an estimated effective dose of several Sv [65]. Moreover, in some reports the probability of short-term SPEs during the round trip to and from Mars is estimated to be as high as $20 \%$ [66]. There is also an additional $\sim 20 \%$ probability of short-term solar particle events (SPEs) during a 12-18 months round trip to Mars, which could conceivably impart a relatively high acute dose of predominantly protons and light ions within an hour or less, which significantly complicates the mission planning [1, 67, 68].

As exposure to large SPEs can be fatal, the toxicity risk associated with using radioprotective agents would be justified. Although some recent studies have focused on traditional or new radioprotectors [69], evidence shows that radiation mitigators could play a more important role during space missions. Currently, amifostine (WR-2721) is the only FDA-approved broad spectrum radioprotector in clinical application [70-73]. Although the mechanism behind the cytoprotective of ami- fostine is still not fully known, it is believed that free-radical scavenging, DNA repair and induction of cellular hypoxia are involved in its radioprotective properties [74]. It has recently been shown that decreasing the oxygen pressure in tissues can be involved in the radioprotective effects of amifostine [75]. Current findings support the efficacy of treatment with amifostine at high-doses $\left(910 \mathrm{mg} \mathrm{m}^{-2}\right) 30$ minutes before exposure to ionizing radiation [76]. Moreover, it has long been known that vitamin $\mathrm{C}$ can play an important role as a radioprotector in radiation accidents or medical exposures [77]. The observed significant radioprotective effect of vitamin $\mathrm{C}$ suggests that this antioxidant agent is a potential non-toxic, low-cost, easily available radiation mitigator which can be used at lethal doses of ionizing radiation (e.g. during and after SPEs) [78].

It has previously been shown that vitamin $\mathrm{C}$ can decrease radiation-induced chromosomal damage in rodents but it was reported that it cannot reduce mortality [79]. Mortazavi et al. in 2014 [80] and Sato et al. in 2015 [81] reported that administration of vitamin $\mathrm{C}$ can be effective even after exposure to sparsely ionizing radiation. However, even if the radiation environment is very different in space, with highly densely ionizing particles, it is worth studying vitamin $\mathrm{C}$ as a possible non-toxic, low-cost, easily available radiation mitigator in space missions. Vitamin $\mathrm{C}$ could be used up to 24 hours after exposure to high levels of ionizing radiation in cases such as the occurrence of SPE. The fact that the vitamin $\mathrm{C}$ can successfully be taken so long time after the exposure will allow the astronauts to both estimate their radiation exposure before choosing any therapeutic intervention, and consult expert physicians/scientists on Earth to make sure about the dosage of vitamin $\mathrm{C}$ and possible other therapeutic agents, as illustrated in Figure 1. It is well known that the space radiation has a negative effect on the eyes of the astronauts [82], and that cataracts are developed if a threshold dose is exceeded. The re- 


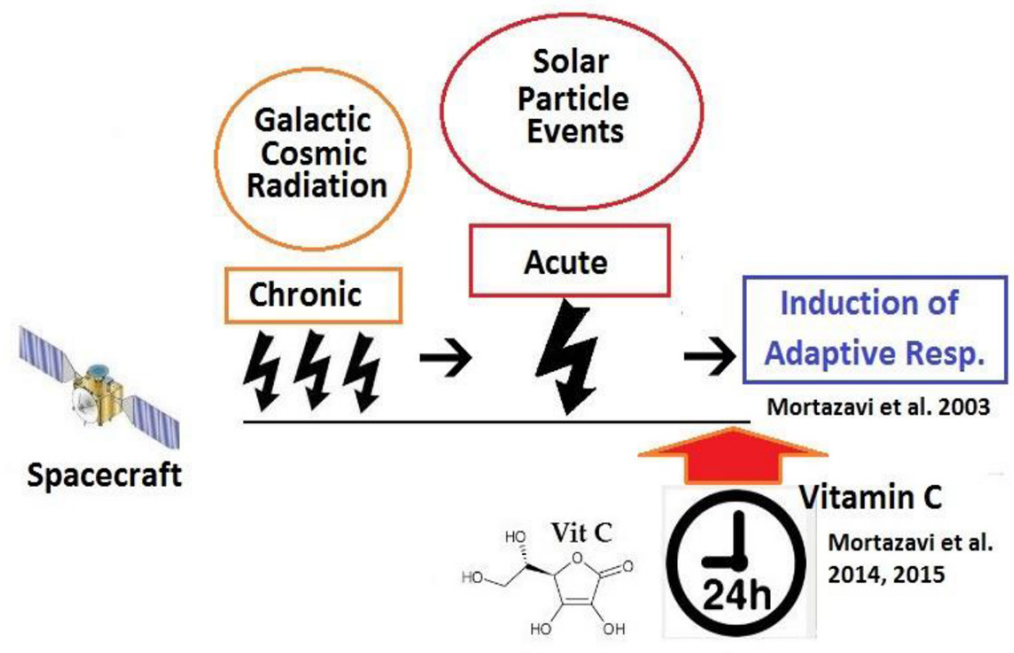

Figure 1: Vitamin C can be used up to 24 hours after exposure to high levels of ionizing radiation (e.g. doses caused by large and solar energetic particles (SPE) $[7,22])$.

cent observation that vitamin $\mathrm{C}$ intake can decrease the risks of getting cataracts is therefore important. Researchers have also observed an inverse association between serum ascorbate and nuclear and posterior subcapsular cataract [83].

\section{Enhancing the Immune System by} Hormetic Responses

Dysregulation of the immune system during spaceflight has been well documented [84, 85]. Disrupted immune system, especially in conjunction with relatively high levels of ionizing radiation and limited clinical care can significantly increase the health risks during manned deep space missions, such as a journey to Mars [85]. Both short and long duration spaceflights can be associated with consistent peripheral phenotype changes and altered cytokine production. However, mission duration may affect the functional immune dysregulation [84]. Developing methods which can improve the immune system of astronauts during long-term missions is therefore very important.

\section{Conclusion}

A journey to Mars would require an extend- ed period of time in deep space, in addition to a possible longer stopover on Mars. This will expose the astronauts to high doses of densely ionization particles. Today, no single countermeasure exists which can reduce the crew exposure/risks to below existing accepted risk limits during the transit periods from Earth to Mars. Even if the dose rate on Mars is lower than in deep space, the astronauts would be exposed to around $40 \%$ of the dose rate in deep space without proper shielding. Developing different countermeasures to reduce the radiation health risks is therefore very important. In addition to passive and active shielding, in vitro pre-flight screening of the candidates to evaluate their level of radioadaptation, due to e.g. adaptive responses, could reduce the radiation induced health risks. Different medical countermeasures will most likely also be needed. In addition to traditional radioprotectors, radiation mitigators might play an important role in future space missions. Intake of vitamin $\mathrm{C}$ has been documented to decrease radiation-induced chromosomal damage in rodents and reduce the risks of getting cataracts, etc. Studies shows also that intake of vitamin C, up to 24 hours after the exposure to high levels of ionizing radiation, can be used for 
reducing the radiation induced health effects. Vitamin $\mathrm{C}$ is therefore a potential non-toxic and cheap radiation mitigator which could be used by astronauts on future long-term deep space missions.

\section{Authors' Contribution}

Sihver S. and Mortazavi S.M.J. developed the theory and made substantial contributions to the design of the work. All authors discussed the results and contributed to the final manuscript.

\section{Conflict of Interest}

None

\section{References}

1. Cucinotta FA. Review of NASA approach to space radiation risk assessments for Mars exploration. Health Phys. 2015;108:131-42. doi: 10.1097/HP.0000000000000255. PubMed PMID: 25551493.

2. Hoffman SJ, Kaplan DI. Human exploration of Mars: the reference mission of the NASA Mars exploration study team. Linthicum Heights; National Aeronautics and Space Administration; 1997.

3. Fry R, Ainsworth E, Blakely E, Boice Jr J, Curtis S, Land C. Radiation protection guidance for activities in low-earth orbit. Report 132; NCRP; 2000. p. 17-151.

4. Zeitlin C, Hassler D, Cucinotta F, Ehresmann, Wimmer-Schweingruber $R$, Brinza $D$, Kang $S$, Weigle G, Böttcher S, Böhm E. Measurements of energetic particle radiation in transit to Mars on the Mars Science Laboratory. Science. 2013;340:1080-4. doi: 10.1126/science.1235989. PubMed PMID: 23723233.

5. Durante M. Space radiation protection: destination Mars. Life Sci Space Res. 2014;1:2-9. doi: 10.1016/j.Issr.2014.01.002. PubMed PMID: 26432587.

6. Sihver L. Transport calculations and accelerator experiments needed for radiation risk assessment in space. Z Med Phys. 2018;18:253-64. doi: 10.1016/j.zemedi.2008.06.013. PubMed PMID: 19205295.

7. Sihver L, Mortazavi SMJ. Radiation Risks and Countermeasures for Humans on Deep Space Missions. IEEE Aerospace Conference; USA: IEEE; 2019. p. 1-10. doi: 10.1109/AER0.2019.8742175.

8. Youngblom JH, Wiencke JK, Wolff S. Inhibition of the adaptive response of human lymphocytes to very low doses of ionizing radiation by the protein synthesis inhibitor cycloheximide. Mutat Res. 1989;227:257-61. doi: 10.1016/01657992(89)90107-3.

9. Wolff S, Afzal V, Wiencke JK, Olivieri G, Michaeli A. Human lymphocytes exposed to low doses of ionizing radiations become refractory to high doses of radiation as well as to chemical mutagens that induce double-strand breaks in DNA. Int $J$ Radiat Biol Relat Stud Phys Chem Med. 1988;53:3947. doi: 10.1080/09553008814550401. PubMed PMID: 3257477.

10. Shadley JD, Afzal V, Wolff S. Characterization of the adaptive response to ionizing radiation induced by low doses of $\mathrm{X}$ rays to human lymphocytes. Radiat Res. 1987;111:511-7. doi: 10.2307/3576936. PubMed PMID: 3659285.

11. Wiencke JK, Afzal V, Olivieri G, Wolff S. Evidence that the $[3 \mathrm{H}]$ thymidine-induced adaptive response of human lymphocytes to subsequent doses of $X$-rays involves the induction of a chromosomal repair mechanism. Mutagenesis. 1986;1:375-80. doi: 10.1093/mutage/1.5.375. PubMed PMID: 3137415.

12. Olivieri G, Bodycote J, Wolff S. Adaptive response of human lymphocytes to low concentrations of radioactive thymidine. Science. 1984;223:594-7. doi: 10.1126/science.6695170. PubMed PMID: 6695170.

13. Feinendegen LE, Evidence for beneficial low level radiation effects and radiation hormesis. $\mathrm{Br} \mathrm{J}$ Radiol. 2005;78:3-7. doi: 10.1259/bjr/63353075. PubMed PMID: 15673519.

14. Feinendegen LE, Pollycove M, Sondhaus CA. Responses to low doses of ionizing radiation in biological systems. Nonlinearity Biol Toxicol Med. 2004;2;143-71. doi: 10.1259/bjr/63353075. PubMed PMID: 15673519.

15. Mortazavi SMJ, Cameron J, Niroomand-Rad A. Adaptive response studies may help choose astronauts for long-term space travel. Adv Space Res. 2003;31:1543-51. doi: 10.1016/s02731177(03)00089-9. PubMed PMID: 12971409.

16. Mortazavi SMJ, Cameron J, Niroomand-Rad A. The life saving role of radioadaptive responses in long-term interplanetary space journeys. Int Cong. 2005;1276:266-7. doi: 10.1016/j.ics.2004.12.019.

17. Takahashi A, Ikeda H, Yoshida Y. Role of HighLinear Energy Transfer Radiobiology in Space Radiation Exposure Risks. International Journal of Particle Therapy. 2018;5(1):151-9. doi: 10.14338/ 
ijpt-18-00013.1.

18. Elmore E, Lao XY, Kapadia R, Swete M, Redpath JL. Neoplastic transformation in vitro by mixed beams of high-energy iron ions and protons. Rad Res. 2011;176:291-302. doi: 10.1667/rr2646.1. PubMed PMID: 21732791.

19. Chancellor JC, Scott GB, Sutton JP. Space radiation: the number one risk to astronaut health beyond low earth orbit. Life. 2014;4:491-510. doi: 10.3390/life4030491. PubMed PMID: 25370382. PubMed PMCID: PMC4206856.

20. Cortese F, Klokov D, Osipov A, Stefaniak J, Moskalev A, Schastnaya J, Cantor C, Aliper A, Mamoshina P, Ushakov I, Sapetsky A. Vive la radioresistance!: converging research in radiobiology and biogerontology to enhance human radioresistance for deep space exploration and colonization. Oncotarget. 2018;9:14692-722. doi: 10.18632/oncotarget.24461. PubMed PMID: 29581875. PubMed PMCID: PMC5865701.

21. Bevelacqua JJ, Welsh J, Mortazavi SMJ. Comments on 'An overview of space medicine. $\mathrm{Br}$ $J$ Anaesth. 2018;120(4):874-6. doi: 10.1016/j. bja.2017.12.015. PubMed PMID: 29576129.

22. Welsh J, Bevelacqua JJ, Keshavarz M, Mortazavi SMJ. Is Telomere Length a Biomarker of Adaptive Re-sponse in Space?. Curious Findings from NASA and Residents of High Background Radiation Areas. J Biomed Phys Eng. 2019;9(3):381-8. doi: 10.31661/jbpe.v9i3Jun.1151. PubMed PMID: 31341884. PubMed PMCID: PMC6613149.

23. Mortazavi SMJ, Bevelacqua JJ, Fornalski KW, Welsh J, Doss M. Comments on "Space: The Final Frontier-Research Relevant to Mars". Health Phys. 2018;114:344-5. doi: 10.1097/ HP.0000000000000823. PubMed PMID: 29360711. PubMed PMCID: PMC5784783.

24. Mortazavi SMJ, Cameron JR, Niroomand-Rad A. Is the adaptive response an efficient protection against the detrimental effects of space radiation. International Cosmic Ray Conference. 2003;7:4299-302.

25. Mortazavi SMJ. How Does Biological Protection Help Astronauts Tolerate High Levels of Radiation During Deep Space Manned Missions? Mechanical Engineering Conference Room; Grove School of Engineering; 2017.

26. Shtemberg AS, Lebedeva-Georgievskaya KB, Matveeva MI, Kudrin VS, Narkevich VB, Klodt PM, Bazyan AS. Effect of space flight factors simulated in ground-based experiments on the behavior, discriminant learning, and exchange of monoamines in different brain structures of rats. Biol Bull. 2014;41:161-7. doi: 10.1134/ S1062359014020095.

27. Shtemberg AS. The problem of organism individual resistance and radioresitance to prolonged space flights factors influence. 35th COSPAR Scientific Assembly; Paris, France: COSPAR; 2004. p. 4216.

28. Bevelacqua JJ, Mortazavi SMJ. Commentary: Human Pathophysiological Adaptations to the Space Environmen. Front Physiol. 2017;8:1116. doi: 10.3389/fphys.2017.01116. PubMed PMID: 29358922. PubMed PMCID: PMC5766677.

29. Bevelacqua, JJ, Welsh J, Mortazavi SMJ. Comments on 'An overview of space medicine. $\mathrm{Br}$ $J$ Anaesth. 2018;120:874-6. doi: 10.1016/j. bja.2017.12.015. PubMed PMID: 29576129.

30. Wheeler KT, Payne V, D'Agostino RB, Walb MC, Munley MT, Metheny-Barlow LJ, Robbins ME. Impact of Breathing 100\% Oxygen on Radiation-Induced Cognitive Impairment. Radiat Res. 2014:182:580-5. doi: 10.1667/RR13643.1. PubMed PMID: 25338095. PubMed PMCID: PMC4321947.

31. Cucinotta FA, Chappell LJ. Non-targeted effects and the dose response for heavy ion tumor induction. Mutat Res. 2010;687:49-53. doi: 10.1016/j. mrfmmm.2010.01.012. PubMed PMID: 20085778.

32. Turker MS, Connolly L, Dan C, Lasarev M, Gauny $\mathrm{S}$, Kwoh E, Kronenberg A Comparison of autosomal mutations in mouse kidney epithelial cells exposed to iron ions in situ or in culture. Radiat Res. 2009;172:558-66. doi: 10.1667/RR1805.1. PubMed PMID: 19883223.

33. Jain MR, Li M, Chen W, Liu T, de Toledo SM, Pandey BN, Li H, Rabin BM, Azzam El, In vivo space radiation-induced non-targeted responses: late effects on molecular signaling in mitochondria. Curr Mol Pharmacol. 2011;4:106-14. doi: 10.2174/1874467211104020106. PubMed PMID: 21166651. PubMed PMCID: PMC3330755.

34. Huff J, Carnell L, Blattnig S, Chappell L, Kerry G, Lumpkins S, Simonsen L, Slaba T, Werneth C. Evidence report: risk of radiation carcinogenesis. Report Number JSC-CN-35748; United States: NTRS; 2016.

35. Ramadan SS, Sridharan V, Koturbash I, Miousse $I R$, Hauer-Jensen M, Nelson GA, Boerma M. A priming dose of protons alters the early cardiac cellular and molecular response to (56) Fe irradiation. Life Sci Space Res. 2016;8:8-13. doi: 10.1016/j. Issr.2015.12.001. PubMed PMID: 26948008. PubMed PMCID: PMC4782196. 
36. Buonanno M, De Toledo SM, Howell RW, Azzam El. Low-dose energetic protons induce adaptive and bystander effects that protect human cells against DNA damage caused by a subsequent exposure to energetic iron ions. J Radiat Res. 2015;56:502-8. doi: 10.1093/jrr/rrv005. PubMed PMID: 25805407. PubMed PMCID: PMC4426929.

37. Zhou G, Bennett PV, Cutter NC, Sutherland BM. Proton-HZE-particle sequential dual-beam exposures increase anchorage-independent growth frequencies in primary human fibroblasts. Radiat Res. 2006;166:488-94. doi: 10.1667/RR0596.1. PubMed PMID: 16953667.

38. Curtis SB, Letaw JR. Galactic cosmic rays and cell-hit frequencies outside the magnetosphere. Adv Space Res. 1989;9:293-8. doi: 10.1016/02731177(89)90452-3. PubMed PMID: 11537306.

39. Bissell M, Warner H, Berger S, Fry R, Hanawalt $P$, Kastan M. Modeling human risk: Cell \& molecular biology in context. Report Number: LBNL-40278; US: NASA; 1977.

40. Aunins TR, Erickson KE, Prasad N, Levy SE, Jones A, Shrestha S, Mastracchio R, Stodieck L, Klaus D, Zea L, Chatterjee A. Spaceflight Modifies Escherichia coli Gene Expression in Response to Antibiotic Exposure and Reveals Role of Oxidative Stress Response. Front Microbiol. 2018:9:310. doi: 10.3389/fmicb.2018.00310. PubMed PMID: 29615983. PubMed PMCID: PMC5865062.

41. Mortazavi SMJ, Zarei S, Taheri M, Tajbakhsh S, Mortazavi SA, Ranjbar S, Momeni F, Masoomi S, Ansari L, Movahedi MM, Taeb S, Haghani M. Sensitivity to Antibiotics of Bacteria Exposed to Gamma Radiation Emitted from Hot Soils of the High Background Radiation Areas of Ramsar, Northern Iran. Int J Occup Environ Med. 2017;8:80-4. doi: 10.15171/ijoem.2017.958. PubMed PMID: 28432369. PubMed PMCID: PMC6679611.

42. Taheri M, Mortazavi SMJ, Moradi M, Mansouri S, Hatam GR, Nouri F. Evaluation of the Effect of Radiofrequency Radiation Emitted From Wi-Fi Router and Mobile Phone Simulator on the Antibacterial Susceptibility of Pathogenic Bacteria Listeria monocytogenes and Escherichia coli. Dose Resp. 2017;15.1-8. doi: 10.1177/1559325816688527. PubMed PMID: 28203122. PubMed PMCID: PMC5298474.

43. Mermel LA. Infection prevention and control during prolonged human space travel. Clin Infect Dis. 2013;56:123-30. doi: 10.1093/cid/cis861. PubMed PMID: 23051761.

44. Wilson JW, Ott CM, Zu Bentrup KH, Ramamurthy
R, Quick L, Porwollik S, Cheng P, McClelland M, Tsaprailis G, Radabaugh T, Hunt A. Space flight alters bacterial gene expression and virulence and reveals a role for global regulator Hfq. Proc Natl Acad Sci USA. 2007;104:16299-304. doi: 10.1073/ pnas.0707155104. PubMed PMID: 17901201. PubMed PMCID: PMC2042201.

45. Crucian B, Stowe R, Mehta S, Uchakin P, Quiriarte H, Pierson D, Sams C, Immune System Dysregulation Occurs During Short Duration Spaceflight On Board the Space Shuttle. J Clin Immun. 2013;33:456-65. doi: 10.1007/s10875-012-98247.

46. Smith SM, Zwart SR, Block G, Rice BL, DavisStreet JE. The nutritional status of astronauts is altered after long-term space flight aboard the International Space Station. J Nutr. 2005;135:43743. doi: 10.1093/jn/135.3.437. PubMed PMID: 15735075.

47. Giardi MT, Touloupakis E, Bertolotto E, Mascetti G. Preventive or Potential Therapeutic Value of Nutraceuticals against Ionizing Radiation-Induced Oxidative Stress in Exposed Subjects and Frequent Fliers. Int J Mol Sci. 2013;14:17168-92. doi: 10.3390/ijms140817168. PubMed PMID: 23965979. PubMed PMCID: PMC3759958.

48. Citrin D, Cotrim AP, Hyodo F, Baum BJ, Krishna MC, Mitchell JB. Radioprotectors and Mitigators of Radiation-Induced Normal Tissue Injury. The Oncologist. 2010;15:360-71. doi: 10.1634/ theoncologist.2009-S104. PubMed PMID: 20413641. PubMed PMCID: PMC3076305.

49. Weiss JF, Landauer MR. History and development of radiation-protective agents. Int J Radiat Biol. 2009;85:539-73. doi: 10.1080/09553000902985144. PubMed PMID: 19557599.

50. Kennedy AR, Davis JG, Carlton W, Ware JH. Effects of dietary antioxidant supplementation on the development of malignant lymphoma and other neoplastic lesions in mice exposed to proton or ironion radiation. Radiat Res. 2008;169:615-25. doi: 10.1667/RR1296.1. PubMed PMID: 18494549. PubMed PMCID: PMC3589916.

51. Cucinotta FA, Manuel FK, Jones J, Iszard G, Murrey J, Djojonegro B, Wear M. Space radiation and cataracts in astronauts. Radiat Res. 2001;156:4606. doi: 10.1667/0033-7587(2001)156[0460:sracia] 2.0.co;2. PubMed PMID: 11604058.

52. Cucinotta FA, Schimmerling W, Wilson JW, Peterson LE, Badhwar GD, Saganti PB, Dicello JF. Space radiation cancer risks and uncertainties for 
Mars missions. Radiat Res. 2001;156:682-8. doi: 10.1667/0033-7587(2001)156[0682:srcrau]2.0. co;2. PubMed PMID: 11604093.

53. Boerma M, Nelson GA, Sridharan V, Mao XW, Koturbash I, Hauer-Jensen M. Space radiation and cardiovascular disease risk. World $\mathrm{J}$ Cardiol. 2015;7:882-8. doi: 10.4330/wjc.v7.i12.882. PubMed PMID: 26730293. PubMed PMCID: PMC4691814.

54. Asselin-Labat ML, Rampersad R, Xu X, Ritchie ME, Michalski J, Huang L, Onaitis MW. High-LET Radiation Increases Tumor Progression in a K-RasDriven Model of Lung Adenocarcinoma. Radiat Res. 2017;188:562-70. doi: 10.1667/RR14794.1. PubMed PMID: 28952911.

55. Sylvester CB, Abe JI, Patel ZS, Grande-Allen KJ. Radiation-Induced Cardiovascular Disease: Mechanisms and Importance of Linear Energy Transfer. Front Cardiovasc Med. 2018;5:5. doi: 10.3389/ fcvm.2018.00005. PubMed PMID: 29445728. PubMed PMCID: PMC5797745.

56. Nukala U, Thakkar S, Krager KJ, Breen PJ, Compadre CM, Aykin-Burns N. Antioxidant Tocols as Radiation Countermeasures (Challenges to be $\mathrm{Ad}$ dressed to Use Tocols as Radiation Countermeasures in Humans). Antioxidants (Basel). 2018;7:215. doi: 10.3390/antiox7020033. PubMed PMID: 29473853. PubMed PMCID: PMC5836023.

57. Schreurs AS, Shirazi-Fard Y, Shahnazari M, Alwood JS, Truong TA, Tahimic CG, Limoli CL, Turner ND, Halloran B, Globus RK. Dried plum diet protects from bone loss caused by ionizing radiation. Sci Rep. 2016;6:21343. doi: 10.1038/ srep21343. PubMed PMID: 26867002. PubMed PMCID: PMC4750446.

58. Kennedy AR, Zhou Z, Donahue JJ, Ware JH. Protection against adverse biological effects induced by space radiation by the Bowman-Birk inhibitor and antioxidants. Radiat Res. 2006;166:327-32. doi: 10.1667/RR3599.1. PubMed PMID: 16881733.

59. Kennedy AR, Ware JH, Guan J, Donahue JJ, Biaglow JE, Zhou Z, Stewart J, Vazquez M, Wan XS. Selenomethionine protects against adverse biological effects induced by space radiation. Free Radic Biol Med. 2004;36:259-66. doi: 10.1016/j.freeradbiomed.2003.10.010. PubMed PMID: 14744637.

60. Cordero RJ. Melanin for space travel radioprotection. Env Microbial. 2017;19:2529-32. doi: 10.1111/1462-2920.13753. PubMed PMID: 28419675.

61. Hu S. Solar Particle Events and Radiation Exposure in Space. 2017. Available from: https://three.
jsc.nasa.gov/articles/Hu-SPEs.pdf.

62. Sanzari JK, Cengel KA, Wan XS, Rusek A, Kennedy AR. Acute hematological effects in mice exposed to the expected doses, dose-rates, and energies of solar particle event-like proton radiation. Life Sciences in Space Research. 2014;2:86-91. doi: 10.1016/j.Issr.2014.01.003. PubMed PMID: 25202654. PubMed PMCID: PMC4155507.

63. McPhee JC, Charles JB. Human health and performance risks of space exploration missions: evidence reviewed by the NASA human research program. NASA; 2009. p. 3405.

64. Hall EJ, Giaccia AJ. Radiobiology for the Radiologist. Lippincott, Williams \& Wilkins; 2012.

65. Kleiman NJ, Stewart FA, Hall EJ. Modifiers of radiation effects in the eye. Life Sci Space Res. 2017;15:43-54. doi: 10.1016/j.Issr.2017.07.005. PubMed PMID: 29198313.

66. Rodman C, Almeida-Porada G, George SK, Moon $\mathrm{J}$, Soker S, et al. In vitro and in vivo assessment of direct effects of simulated solar and galactic cosmic radiation on human hematopoietic stem/progenitor cells. Leukemia. 2017;31(6):1398-407. doi: 10.1038/leu.2016.344. PubMed PMID: 27881872. PubMed PMCID: PMC5870806.

67. Rapp D. MARS Mars Life Support Systems. Mars. 2006;2:72-82. doi: 10.1555/mars.2006.0004.

68. Rapp D. Human Missions to Mars. Springer; 2008.

69. Kennedy AR. Biological Effects of Space Radiation and Development of Effective Countermeasures. Life Sci Space Res (Amst). 2014;1:10-43. doi: 10.1016/j.Issr.2014.02.004. PubMed PMID: 25258703. PubMed PMCID: PMC4170231.

70. Rajan Radha R, Chandrasekharan G. Pulmonary injury associated with radiation therapy - Assessment, complications and therapeutic targets. Biomed Pharmacother. 2017;89:1092-104. doi: 10.3390/ijms20163876. PubMed PMID: 31398940. PubMed PMCID: PMC6719901.

71. Bourgier C, Levy A, Vozenin MC, Deutsch E. Pharmacological strategies to spare normal tissues from radiation damage: useless or overlooked therapeutics? Cancer Metastasis Rev. 2012;31:699-712. doi: 10.1007/s10555-012-9381-9. PubMed PMID: 22706781.

72. Kuntic VS, Stankovic MB, Vujic ZB, Brboric JS, Uskokovic-Markovic SM. Radioprotectors - the evergreen topic. Chem Biodivers. 2013;10:1791-803. doi: 10.1002/cbdv.201300054. PubMed PMID: 24130023.

73. Szejk M, Kołodziejczyk-Czepas J, Żbikowska HM. Radioprotectors in radiotherapy-advances in the 
potential application of phytochemicals. Postepy Hig Med Dosw (Online). 2016;70:722-34. doi: 10.5604/17322693.1208039. PubMed PMID: 27356603.

74. Kouvaris JR, Kouloulias VE, Vlahos LJ. Amifostine: the first selective-target and broad-spectrum radioprotector. Oncologist. 2007;12:738-47. doi: 10.1634/theoncologist.12-6-738. PubMed PMID: 17602063.

75. Ueno M, Matsumoto S, Matsumoto A, Manda S, Nakanishi I, Matsumoto KI, Mitchell JB, Krishna MC, Anzai K. Effect of amifostine, a radiationprotecting drug, on oxygen concentration in tissue measured by EPR oximetry and imaging. $J$ Clin Biochem Nutr. 2017;60:151-5. doi: 10.3164/ jcbn.15-130. PubMed PMID: 28584395. PubMed PMCID: PMC5453015.

76. Langell J, Jennings R, Clark J, Ward JB. Pharmacological agents for the prevention and treatment of toxic radiation exposure in spaceflight. Aviat Space Environ Med. 2008;79:651-60. doi: 10.3357/ asem.2113.2008. PubMed PMID: 18619123.

77. Narra VR, Howell RW, Sastry KS, Rao DV. Vita$\min C$ as a radioprotector against iodine- 131 in vivo. J Nucl Med. 1993;34:637-40. PubMed PMID: 8455081.

78. Mortazavi SMJ, Foadi M, Mozdarani H, Haghani M, Mosleh MA, et al. Future role of vitamin $\mathrm{C}$ in radiation mitigation and its possible applications in manned deep space missions: Survival study and the measurement of cell viability. Int $J$ Radiat Res (IJRR). 2015;13(1):55-60.

79. Mettler Jr FA, Brenner D, Coleman CN, Kaminski JM, Kennedy AR, Wagner LK. Can radiation risks to patients be reduced without reducing radiation exposure? The status of chemical radiopro- tectants. AJR AM. 2011;196:616-8. doi: 10.2214/ AJR.10.4959. PubMed PMID: 21343505.

80. Mortazavi SMJ, Sharif-Zadeh S, Mozdarani H, Foadi $M$, Haghani M, Sabet E. Future role of vitamin $C$ in radiation mitigation and its possible applications in manned deep space missions: Survival study and the measurement of cell viability. Physica Medica: European Journal of Medical Physics. 2014;3:e97. doi: 10.1016/j.ejmp.2014.07.278.

81. Sato T, Kinoshita M, Yamamoto T, Ito M, Nishida T, Takeuchi M, Saitoh D, Seki S, Mukai Y. Treatment of irradiated mice with high-dose ascorbic acid reduced lethality. PLoS One. 2015;10:e0117020. doi: 10.1371/journal.pone.0117020. PubMed PMID: 25651298. PubMed PMCID: PMC4317183.

82. Mao XW, Pecaut MJ, Stodieck LS, Ferguson VL, Bateman TA, Bouxsein M, Jones TA, Moldovan M, Cunningham CE, Chieu J, Gridley DS. Spaceflight environment induces mitochondrial oxidative damage in ocular tissue. Radiat Res. 2013;180:340-50. doi: 10.1667/RR3309.1. PubMed PMID: 24033191.

83. Wei L, Liang G, Cai C, Lv J. Association of vitamin $\mathrm{C}$ with the risk of age-related cataract: a metaanalysis. Acta Ophthalmol. 2016;94:e170-6. doi: 10.1111/aos.12688. PubMed PMID: 25735187.

84. Crucian BE, Stowe RP, Pierson DL, Sams CF. Immune system dysregulation following short-vs long-duration spaceflight. Aviat Space Environ Med. 2008;79:835-43. doi: 10.3357/asem.2276.2008. PubMed PMID: 18785351.

85. Crucian B, Simpson RJ, Mehta S, Stowe R, Chouker A, Hwang SA, Actor JK, Salam AP, Pierson D, Sams C. Terrestrial stress analogs for spaceflight associated immune system dysregulation. Brain Behav Immun. 2014;39:23-32. doi: 10.1016/j. bbi.2014.01.011. PubMed PMID: 24462949. 